This item was submitted to Loughborough's Research Repository by the author.

Items in Figshare are protected by copyright, with all rights reserved, unless otherwise indicated.

\title{
Predicted vs. actual energy performance of non-domestic buildings: using post-occupancy evaluation data to reduce the performance gap
}

PLEASE CITE THE PUBLISHED VERSION

http://dx.doi.org/10.1016/j.apenergy.2011.11.075

PUBLISHER

(C) Elsevier

VERSION

AM (Accepted Manuscript)

\section{LICENCE}

CC BY-NC-ND 4.0

\section{REPOSITORY RECORD}

de Menezes, Anna Carolina Kossmann, Andrew Cripps, Dino Bouchlaghem, and Richard A. Buswell. 2019. "Predicted Vs. Actual Energy Performance of Non-domestic Buildings: Using Post-occupancy Evaluation Data to Reduce the Performance Gap". figshare. https://hdl.handle.net/2134/9937. 
This item was submitted to Loughborough's Institutional Repository (https://dspace.lboro.ac.uk/) by the author and is made available under the following Creative Commons Licence conditions.

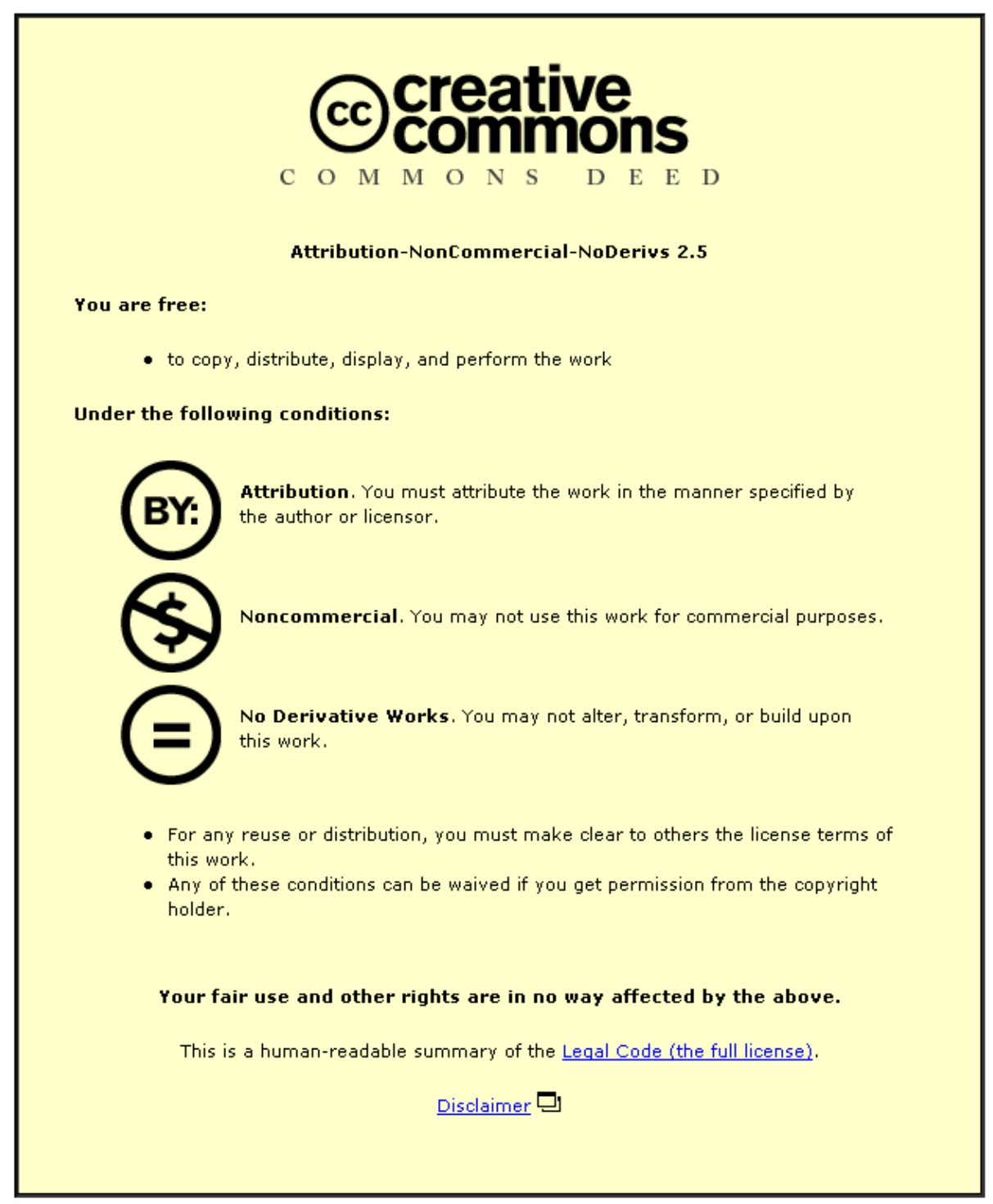

For the full text of this licence, please go to: http://creativecommons.org/licenses/by-nc-nd/2.5/ 


\title{
Predicted vs. Actual Energy Performance of Non-Domestic Buildings: Using Post Occupancy Evaluation Data to Reduce the Performance Gap
}

\author{
Anna Carolina MENEZES ${ }^{[1,2]}$, Andrew CRIPPS ${ }^{[1]}$, Dino BOUCHLAGHEM ${ }^{[2]}$, Richard \\ BUSWELL ${ }^{[2]}$
}

[1] AECOM, Building Engineering, MidCity Place, 71 High Holborn, London, WC1V 6QS, UK [2] Loughborough University, Centre for Innovative and Collaborative Construction Engineering, Loughborough, Leicestershire, LE11 3TU, UK

\begin{abstract}
With the increasing demand for more energy efficient buildings, the construction industry is faced with the challenge to ensure that the energy performance predicted during the design stage is achieved once a building is in use. There is, however, significant evidence to suggest that buildings are not performing as well as expected and initiatives such as PROBE and CarbonBuzz aim to illustrate the extent of this so called 'performance gap'. This paper discusses the underlying causes of discrepancies between energy modelling predictions and in-use performance of occupied buildings (after the twelve month liability period). Many of the causal factors relate to the use of unrealistic input parameters regarding occupancy behaviour and facilities management in building energy models. In turn, this is associated with the lack of feedback to designers once a building has been constructed and occupied.
\end{abstract}

The paper aims to demonstrate how knowledge acquired from Post-Occupancy Evaluation (POE) can be used to produce more accurate energy performance models. A case study focused specifically on lighting, small power and catering equipment in a high density office building is analysed and presented. Results show that by combining monitoring data with predictive energy modelling, it was possible to increase the accuracy of the model to within $3 \%$ of actual electricity consumption values. Future work will seek to use detailed POE data to develop a set of evidence based benchmarks for energy consumption in office buildings. It is envisioned that these benchmarks will inform designers on the impact of occupancy and management on the actual energy consumption of buildings. Moreover, it should enable the use of more realistic input parameters in energy models, bringing the predicted figures closer to reality.

\section{Keywords}

Building energy modelling; energy benchmarks; energy performance; performance gap; postoccupancy evaluation

\subsection{Introduction}

There is extensive evidence to suggest that buildings usually do not perform as well as predicted [1-4]. This is often attributed to the lack of feedback to designers after handover, inhibiting improvements both to existing buildings and future designs. The practice of Post-Occupancy Evaluation (POE) aims to address this issue by evaluating the performance of a building after it has been built and occupied to provide designers with valuable feedback on its actual performance inuse. This paper aims to demonstrate how knowledge acquired from POE can be used to produce more accurate energy performance models. The study focuses on electricity consumption due to lighting, small power and catering equipment, rather than thermal loads.

In recent years, Building Regulations in England and Wales have become increasingly stringent, demanding higher standards of energy performance. This can be linked to the implementation of the European Energy Performance of Buildings Directive (EBPD) as well as the Government's legally binding commitment to reduce UK carbon dioxide emissions by $80 \%$ by 2050 in relation to the 
1990 baseline [5]. As a result, all new buildings must achieve a Building Energy Rating (BER) lower than the prescribed Target Energy Rating (TER) for the specific building type, calculated using a Simplified Building Energy Model (SBEM). However, this methodology does not aim to predict the actual energy consumption of a building, as its purpose is solely to ensure compliance with Building Regulations. Instead, detailed Dynamic Simulation Models (DSMs) can be used to obtain predictions of in-use energy performance. DSMs are more suited to the functional and volumetric complexities of non-domestic buildings as they allow for more detailed input options whilst also containing extensive databases for materials and systems [6]. Despite these and many other added capabilities, there is still a significant gap between predicted and actual energy consumption in non-domestic buildings [2]. This discrepancy is commonly referred to as the 'performance gap'.

\subsection{The Performance Gap}

The PROBE studies (Post-occupancy Review of Buildings and their Engineering) investigated the performance of 23 buildings previously featured as 'exemplar designs' in the Building Services Journal (BSJ) [3,4]. The research project ran from 1995 to 2002, highlighting the lack in feedback regarding the actual performance of buildings. It also brought to light the so called 'performance gap', suggesting that actual energy consumption in buildings will usually be twice as much as predicted [4]. More recently, initiatives such as the Low Carbon Buildings Accelerator and the Low Carbon Buildings Programme, have aimed to provide feedback regarding the performance of buildings in-use [7]. Findings from both these studies have been published by the Carbon Trust in a series of reports, with one dedicated solely to the performance gap [8]. The report entitled 'Closing the Gap' introduces the underlying causes of the performance gap, highlighting that design predictions for regulatory compliance do not account for all energy uses in buildings. Data from five case study buildings is used to illustrate the discrepancies between actual regulated energy consumption and modelling output used for compliance with building regulations. Results demonstrate that the actual regulated consumption can be five times higher than predicted [8].

In 2008, the Royal Institute of British Architects (RIBA) and the Chartered Institution of Building Services Engineers (CIBSE) launched CarbonBuzz, a free online platform allowing practices to share and publish building energy consumption data anonymously [9]. It enables designers to compare predicted and actual energy use for their projects, whilst also allowing for comparison against benchmarks and data supplied by other participating practices. Figure 1 illustrates the predicted and actual electricity consumption in three building sectors: schools, general offices and university buildings [10]. The graph depicts the median predicted and median consumption for the buildings within the database, which are assumed to be broadly representative of each sector. As shown, the measured electricity demands are approximately $60 \%$ to $70 \%$ higher than predicted in both schools and general offices, and over $85 \%$ higher than predicted in university campuses.

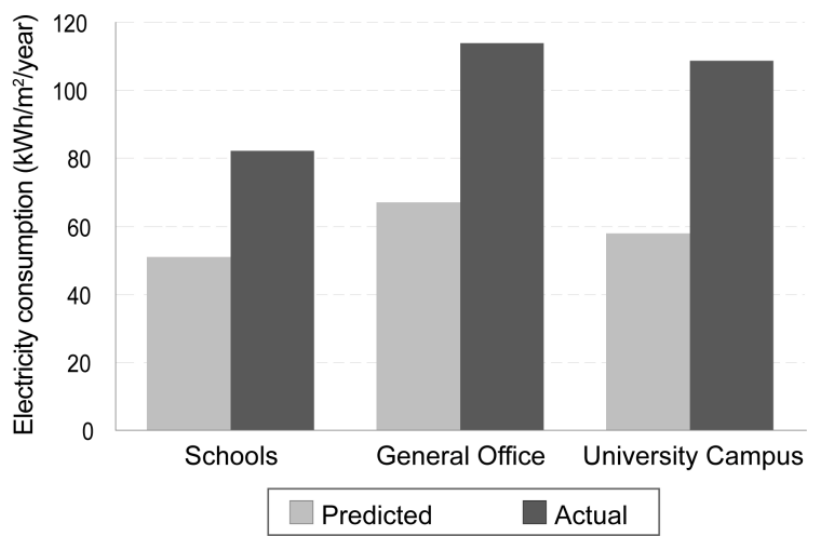

Figure 1: CarbonBuzz median electricity consumption per sector - predicted vs. actual [10].

\subsection{Sources of Discrepancy}

Results from the PROBE studies suggest that such discrepancies transcend the expected shortcomings of current modelling programs; being a result of poor assumptions, as well as a lack of monitoring following construction $[3,4]$. Table 1 summarises the main causes of discrepancies between predicted and actual energy performance in buildings. 


\begin{tabular}{|c|c|}
\hline & Causal factors \\
\hline \multirow{4}{*}{$\begin{array}{l}\text { Predicted } \\
\text { Performance }\end{array}$} & Design Assumptions \\
\hline & $\begin{array}{l}\text { The input of data into a building energy model relies significantly on assumptions, which often go unchallenged. These are usually } \\
\text { made at design stage when many aspects of the building's function and use are unknown or uncertain, and will frequently be } \\
\text { based on the designer's own experience. This can result in oversimplified and/or unrealistic inputs regarding the built quality and } \\
\text { fabric performance, occupancy patterns and behaviour as well as the management and control of the building and its services [13]. }\end{array}$ \\
\hline & Modelling Tools \\
\hline & $\begin{array}{l}\text { Building energy modelling software can contain fundamental errors embedded in the equations used by the program, leading to } \\
\text { inaccuracies in the predictions. This should be avoided by choosing modelling tools that have been appropriately validated } \\
\text { according to the procedures defined by CIBSE TM33 [14]. The choice of software should also consider the specific type of building } \\
\text { being modelled and should allow for adequate representation of the building itself as well as its use and operation. Restrictive or } \\
\text { oversimplified tools can result in models that are unrepresentative of reality [13]. }\end{array}$ \\
\hline \multirow{6}{*}{$\begin{array}{l}\text { Actual } \\
\text { Performance }\end{array}$} & Management and Controls \\
\hline & $\begin{array}{l}\text { Facilities managers (FM) have control over central plant equipment, accounting for a great portion of the energy consumption in a } \\
\text { building (especially in highly automated buildings). Good management and controls can result in an efficient operation of the } \\
\text { building services whilst inappropriate strategies can result in unnecessary waste of energy [4]. Frequent energy audits as well as } \\
\text { re-commissioning exercises can help maximise the efficiency of building services, avoiding unnecessary energy waste [15]. }\end{array}$ \\
\hline & Occupancy Behaviour \\
\hline & $\begin{array}{l}\text { Building occupants do not always have direct control over building services such as heating and cooling, yet even in highly } \\
\text { automated buildings, occupants can affect their energy consumption by influencing the internal conditions (e.g. opening windows, } \\
\text { blocking air inlets/outlets, etc) [1]. Moreover, occupants have control over various energy consuming equipment and appliances, } \\
\text { commonly referred to as 'unregulated loads' (i.e. not controlled by Building Regulations). }\end{array}$ \\
\hline & Built Quality \\
\hline & $\begin{array}{l}\text { The in-use energy performance of a building is affected by the quality of its construction. Issues such as gaps in the insulation and } \\
\text { thermal bridging are common, but are rarely considered in the predictions of energy consumption. Moreover, changing requests } \\
\text { from clients and/or value engineering exercises can result in significant deviations from what was originally specified [2]. Yet these } \\
\text { alterations are rarely fed back into the energy model. }\end{array}$ \\
\hline
\end{tabular}

Table 1: Causes of discrepancies between predicted and actual energy performance.

As shown, the causal factors relate to both predictive and in-use performance, implying that current predictions tend to be unrealistically low whilst actual energy performance is usually unnecessarily high. However, the overall problem could be interpreted as an inability of current modelling methods to represent realistic use and operation of buildings. This in turn can be associated with the lack of feedback regarding actual use and operation of buildings as well as the resulting energy consumption. Currently, there is a significant lack of information concerning the actual energy performance of our existing building stock [11]. A continued absence of such data is likely to lead to a progressive widening of the gap between theory and practice and a failure to achieve strategic goals [12].

Recent developments in the field of thermal modelling have resulted in increasingly complex simulation software based on calculations of dynamic heat transfer. In addition, stringent procedures are being implemented to ensure the validity of a range of modelling programs [13]. As a result, the impact of modelling tools on the overall discrepancy between predicted and actual performance is consistently being diminished. Meanwhile, some issues with built quality are slowly being tackled by the construction industry, encouraging more airtight buildings and better construction techniques. Extensive research on the actual performance of built elements is also being conducted, whilst most modelling software now allow for assumptions regarding the built quality of specific building elements.

Despite these improvements, current simulation tools do not accurately model the impact of occupants and management on the energy performance of buildings. This is usually attributed to the use of inadequate assumptions at design stage, more so than an inability of the modelling tools themselves. As such, there is scope for further investigation into the actual use of buildings, focusing on occupancy and management behaviour, as well as their impact on unregulated energy consumption. This can be achieved through the practice of Post-Occupancy Evaluation (POE).

\subsection{Post-Occupancy Evaluation}

Post-Occupancy Evaluation (POE) is a structured process of evaluating the performance of a building after it has been built and occupied. This is achieved through systematic data collection, analysis and comparison with explicitly stated performance criteria, providing designers with valuable information regarding the in-use performance of their designs [16]. 
The scope of POE can be divided into three strands [17]:

- Feedback: a management aid mechanism aimed at measuring building performance mostly as an indicator of business productivity and organisational efficiency.

- Feed-forward: aims at improving building procurement through the use of acquired data as feedback to the design team and future briefings.

- Benchmarking: aims at measuring progress striving towards increasingly sustainable construction and stricter targets of energy consumption.

POE can take several approaches, varying from highly technological methodologies involving hard data, to socio-psychological interests where more subjective parameters are used to evaluate the performance of a building. Hence, the method to be undertaken in a POE is usually defined by the objectives being pursued and the areas of interest to the stakeholder. Seeing as POE concerns the analysis of individual buildings, the methods vary in scale, type, level of interactivity and suitability for specific projects [18]. As a consequence, a vast number of POE methods and techniques are available worldwide, allowing for an array of different evaluations to be performed in numerous types of buildings.

One of the most widely recognised tools for evaluating the energy performance of buildings in the UK is the Energy Assessment and
Reporting Methodology (EARM). Originally developed for the PROBE studies, it was later published by CIBSE as a technical memorandum (CIBSE TM22). The document describes a method for assessing the energy performance of an occupied building based on metered energy use, and includes a software implementation of the method. It can be used to identify poorly performing buildings and systems, indicating the causes of poor performance and benchmarking procedures [19]. Figure 2 illustrates the underlying structure of the TM22 methodology, depicting the breakdown of energy consumption by enduses (such as lighting and ventilation) whilst highlighting the impact of low-level factors such as hours of use and equipment efficiency.

The first edition of TM22, published in 1999, consisted of 3 stages:

- Stage 1: a quick assessment of the energy consumption, breaking it down into use per unit floor area and can be carried out by inhouse resources. Information required includes description of the building, floor area and annual energy consumption records.

- Stage 2: a more detailed assessment of the energy consumption including special energy uses or occupancy and can usually be carried out in-house. Information required includes details of building occupancy and usage as well as any special or unusual uses.

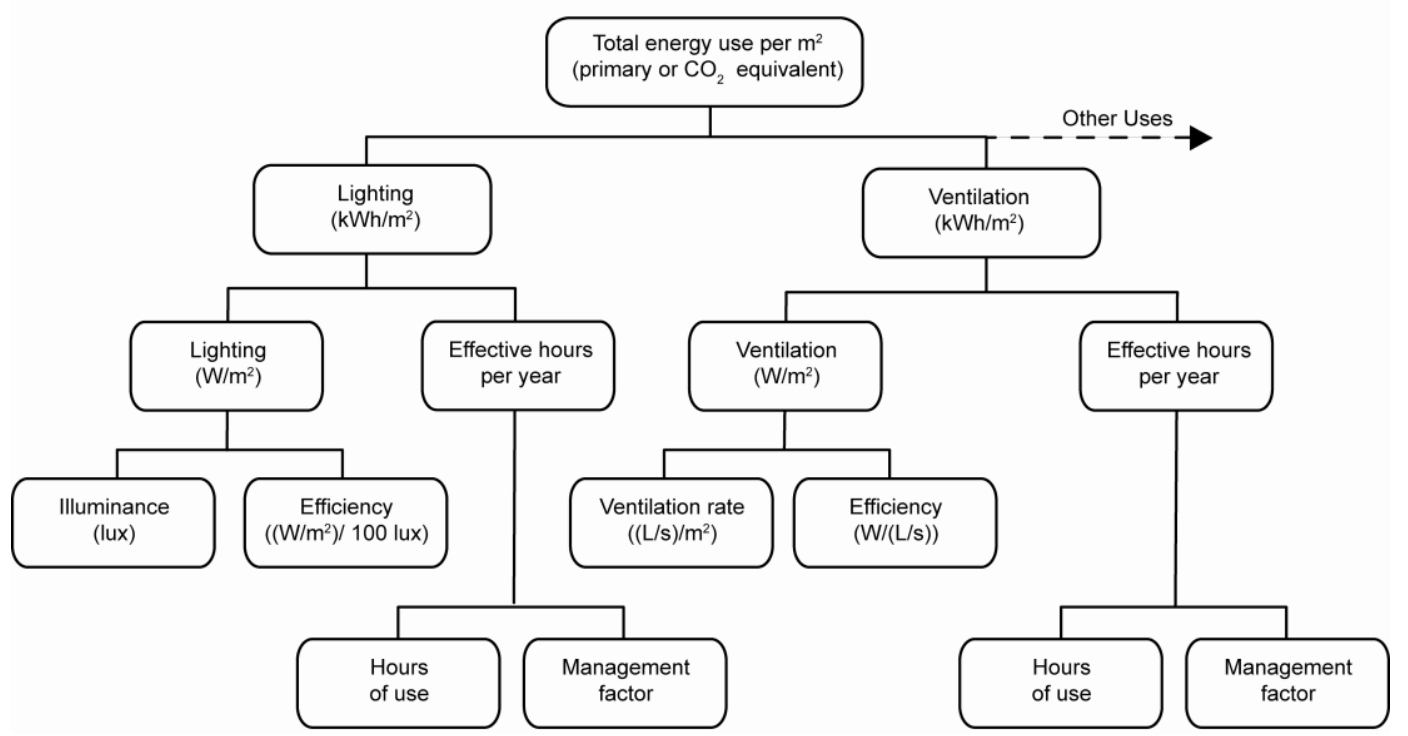

Figure 2: TM22 ‘Energy Tree Diagram’ illustrating the breakdown of energy use [19]. 
- Stage 3: a full understanding of the performance of the building and its systems, and will usually require a specialist to carry out the assessment. Required information includes building operation and maintenance manuals as well as details of building occupancy, use and cleaning, plant operation procedures and schedules.

In 2006, a second edition of the TM22 was published, updating the previous edition by describing procedures for compliance with emerging energy performance legislation [20]. It also included treatment of on-site energy generation and renewable energy sources. Overall, it provided a simpler and more effective method for energy assessment and reporting, whilst keeping up to date with current developments in the construction industry. An updated version of TM22 is currently being developed and will be used as a guidance framework for the Technology Strategy Board's Building Performance Evaluation call [21]. This government-funded programme is anticipated to be the largest POE study ever to be conducted in the UK, evaluating the in-use performance of both domestic and nondomestic buildings. One of the key objectives of the programme is to assemble a substantial body of data for a variety of building types, aiming to draw conclusions on the in-use performance of various design strategies. These will be disseminated across the industry to enable improvements in the performance of new and refurbished buildings through better design, delivery and operation.

\subsection{Methodology}

Taking a case study approach, this paper analyses the energy performance of an office building in central London. The assessment was guided by the TM22 methodology, followed by in-depth monitoring of the electricity consumption for lighting, small power and catering equipment. Monitoring of occupancy patterns were also conducted via half-hourly walkthrough inspections. Results from the monitoring exercise were then fed into energy models, aiming to produce more accurate predictions of energy consumption. These focused solely on tenant electricity consumption, excluding all gas usage as well as electricity consumption for air conditioning, ventilation, lifts, water heating and circulation, as well as lighting in communal areas.

\subsection{Building Description}

The selected building accommodates the offices of four different companies throughout its seven floors and basement. It includes an atrium that extends to all floors (except the basement). Each floor comprises a main openplan office space with a treated floor area of approximately $2,000 \mathrm{~m}^{2}$. The ground floor houses a large reception area and the basement houses meeting rooms and cellular offices. The building is fully air-conditioned, three rooftop air-handling units (AHUs) provide heating/cooling as well as fresh air to all floors and atrium. A separate system provides heating for the basement, whilst fan coil units (FCUs) provide cooling to the meeting rooms and small individual offices. Two gas-fired boilers provide hot water to all toilets and kitchens throughout the building.
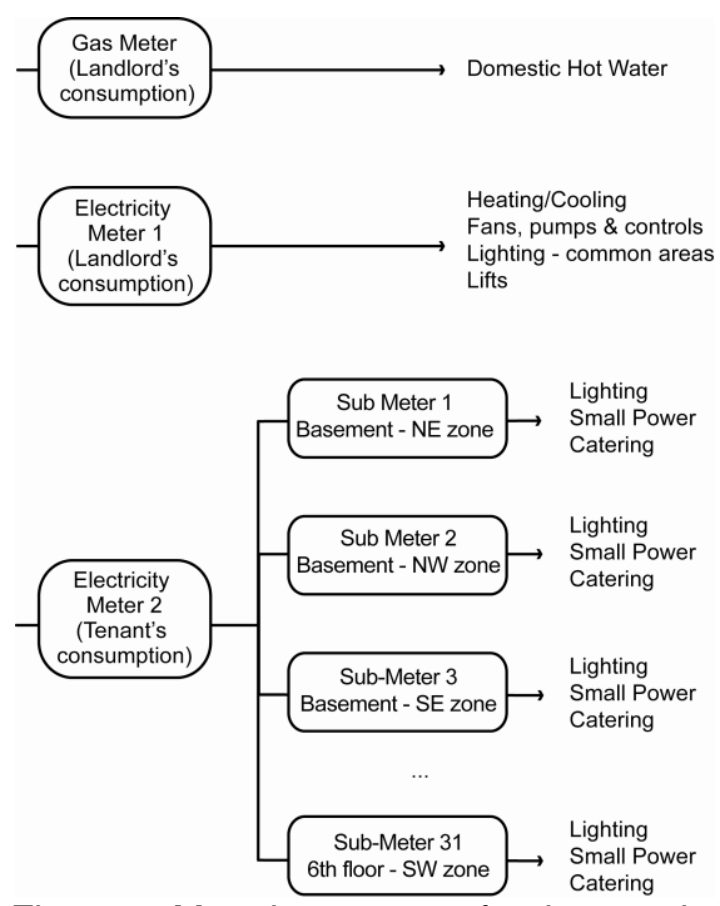

Figure 3: Metering strategy for the supply of gas and electricity to the building.

Figure 3 illustrates the metering strategy for the supply of electricity and gas to the building. As shown, the landlord is responsible for the electricity consumed by all air conditioning equipment including the AHUs, FCUs, chillers, pumps and fans as well as the Building Management System (BMS) and other control equipments. The lighting throughout the common areas of the building as well as the toilets is also supplied and maintained by the 
landlord. As such, the energy supplied for the landlord services is metered together, with no sub-metering for individual end-uses. Meanwhile, the electricity supplied to the tenants for lighting, small power equipment and catering in each of the floors is metered separately. A total of 31 sub-meters provide a further breakdown for each of the 4 zones in each floor: North-East (NE), Northwest (NW), Southeast (SE) and Southwest (SW).

\subsection{Monitoring Process}

Following a full TM22 assessment of the building, whereby the total energy consumption for both gas and electricity was analysed and broken down by individual end-use, a further analysis of the tenants' consumption was undertaken. This in-depth study focused on the electricity consumption for lighting, small power and catering within each of the tenant zones, relying on monthly meter readings for each of the sub-meters as well as half hourly profiles acquired through the use of 3-phase portable data loggers connected to the individual subcircuits. Further data was acquired using combined plug monitor / loggers connected to individual small power office equipment such as laptops, computer screens and docking stations. These were also used to monitor the electricity consumption of catering equipment such as fridges, microwave ovens and coffee machines. Half hourly profiles for each of the pieces of equipment being monitored were reviewed in order to obtain an average daily consumption value. Where different usage modes were present (such as stand-by mode), these were recorded separately and accounted for when calculating the average daily consumption for each equipment. Occupancy patterns were also monitored by manually recording the number of occupants within the office in half-hour intervals.

\subsection{Monitoring Results}

Figure 4 illustrates the annual tenant electricity consumption per floor (normalised by $\mathrm{m}^{2}$ ). This includes lighting, small power and catering equipment loads. It is worth noting that the lighting specification and controls are consistent throughout the entire building and the catering facilities in each floor are of a similar size and nature (consisting mainly of an instant hot water heater, a microwave, a dishwasher and a full size fridge). Some floors have additional coffee machines and/or vending machines, and the tenants on the ground floor have a large bar with multiple fridges. In regards to small power, a fairly consistent volume of office equipment is present throughout the building. Despite their different nature of work, all 4 tenant companies have similar occupation densities and office equipment specifications. Most workstations consist of a computer screen, laptop and docking station as well as phone. Some workstations have individual desk lamps, personal fans and/or desktop printers. In addition, all floors have large printer/copiers (typically 6-8 per floor) as well as projectors and/or flat screen displays in meeting rooms.

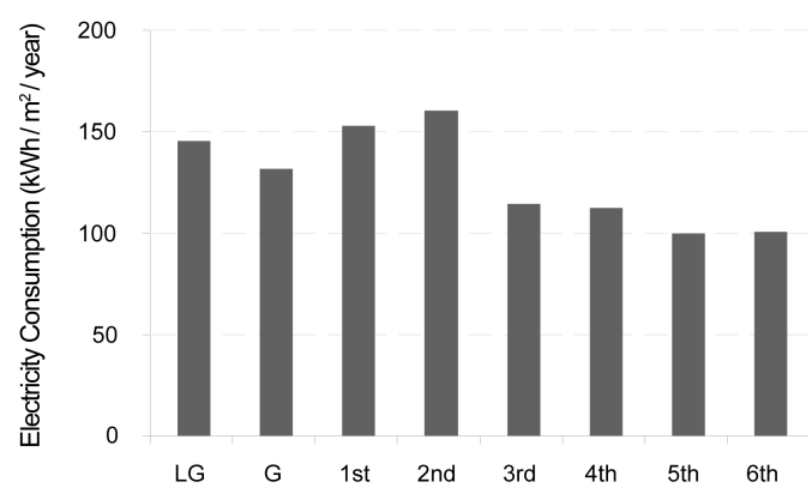

Figure 4: Annual tenant electricity consumption per floor area.

As seen, the 2nd floor consumes approximately $60 \%$ more electricity per $\mathrm{m}^{2}$ than the lowest consumer (5th floor). This is quite a significant variation considering the consistency in lighting specification and controls as well as the similarities in installed equipment and occupation density. However, when relating the electricity consumption to the tenants occupying each of the floors, a clearer pattern can be observed. Figure 5 illustrates how the different tenant companies are located throughout the building. As shown, the lowest consuming floors (5th and 6th) are wholly occupied by Tenant C. Similarly, the 3rd and 4th floors are mainly occupied by Tenant B, presenting similar annual consumption values.

Figure 6 illustrates the annual electricity consumption of each tenant per $\mathrm{m}^{2}$ of office space they occupy. Not surprisingly, Tenant C has the lowest electricity consumption at 90 $\mathrm{kWh} / \mathrm{m}^{2}$. Tenant $A$ has the highest annual consumption at $155 \mathrm{kWh} / \mathrm{m}^{2}$, followed closely by Tenant $D$ at $139 \mathrm{kWh} / \mathrm{m}^{2}$. This might explain 
why the 2nd floor has the highest consumption seeing as it is occupied by both Tenants $A$ and D.

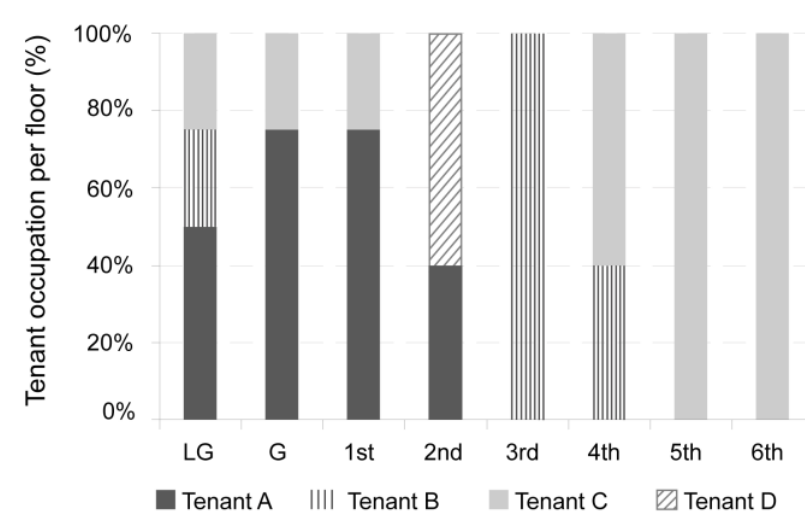

Figure 5: Location of tenant companies throughout the building.

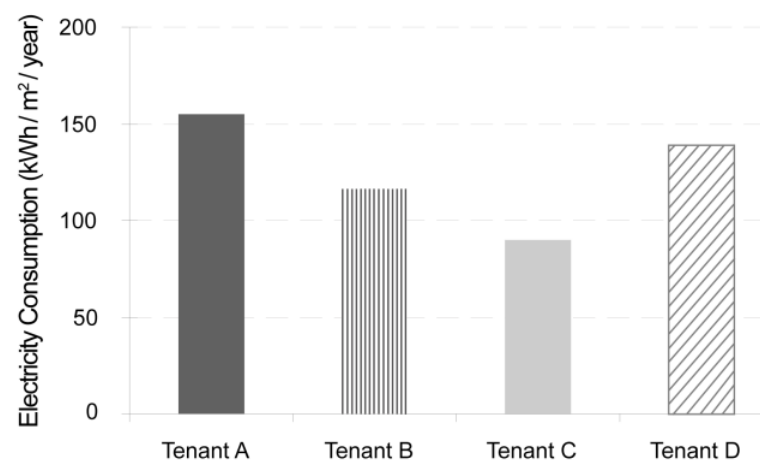

Figure 6: Annual electricity consumption per tenant (normalised by floor area).

An informal interview was conducted with the facilities co-ordinator of each tenant to investigate the causes of such variations. This revealed that the employees of Tenant $A$ are instructed to leave their computers on overnight for IT upgrades. As such, a large quantity of electricity is used outside the normal operating hours of the building, accounting for a significant portion of their overall consumption. Similarly, employees of Tenant $D$ often leave their computers on at the end of the day so that time-consuming tasks, such as high quality rendering, can be performed overnight. On the other hand, employees of Tenants $B$ and $C$ are heavily encouraged to save energy through internal communications to turn off their computers and screens at the end of the day. Tenant B has also instructed their facilities coordinator to switch off printer/copiers and nonessential catering equipment such as coffee machines at the end of each day.

\subsection{Detailed Analysis of Electricity Demand}

Following the analysis of annual electricity consumption data, an in-depth study was undertaken to examine the variation in electricity demand throughout a typical week. Figure 7 illustrates the half hourly electricity consumption for a single zone in the 4th floor of the building (occupied by Tenant B).

As shown, the base load is approximately 3 $\mathrm{kWh} / \mathrm{m}^{2}$ outside working hours. The electricity demand starts to escalate around 06:00 peaking at approximately $13 \mathrm{kWh} / \mathrm{m}^{2}$ by $10: 00$. This can be associated with the arrival of employees who trigger the motion sensors, turning on the lights. This will usually be followed by office/catering equipment being turned on. From 10:00 to 17:00 the demand remains fairly high, varying between 11-14 $\mathrm{kWh} / \mathrm{m}^{2}$, eventually decreasing to approximately $8 \mathrm{kWh} / \mathrm{m}^{2}$ by $19: 30$. This can be associated with equipment being turned off as employees leave the office. A steep rise in the demand is then observed at approximately 20:30, followed by a fairly quick decrease, bringing the demand down to the base load at around 22:00. This late peak can be associated with the cleaning schedule of the building. It is assumed that the rise in demand is due to the use of vacuum cleaners as well as the dishwasher being turned on. The electricity demand during the weekend is fairly constant at a similar base load to the evenings. The only deviation occurs on Saturday between 9:00 and 15:00 when the electricity demand rises to approximately $5 \mathrm{kWh} / \mathrm{m}^{2}$. This can be associated to individual employees going into the office to work extra hours.

The analysis of half hourly electricity consumption has suggested a high correlation between occupancy hours and electricity consumption. In order to determine the extent of this correlation, real occupancy levels were monitored and plotted against the half hourly electricity consumption. Figure 8 illustrates the results of this monitoring showing occupancy patterns on a typical working day. As shown, the electricity demand follows the monitored occupancy profile quite closely. The initial peak in demand is observed around 08:00 when occupancy numbers start to increase rapidly. 
Similarly, a steep decrease in electricity demand is observed after 17:30 when occupancy starts to decrease. However during lunchtime, the quick decrease in occupancy is not reflected in the electricity demand. This is because most computers are kept on and lighting levels remain constant. As previously mentioned, the sharp peak around 20:00 is associated with the cleaning.
Figure 8 also illustrates the standard occupancy profile for offices used by SBEM for compliance predictions. Despite its simplistic nature, standard profiles such as this are normally used in DSMs. As shown, there is little correlation between the SBEM profile and the monitored electricity consumption. The impact of using a standard occupancy profile in predictive models is discussed in further detail below.

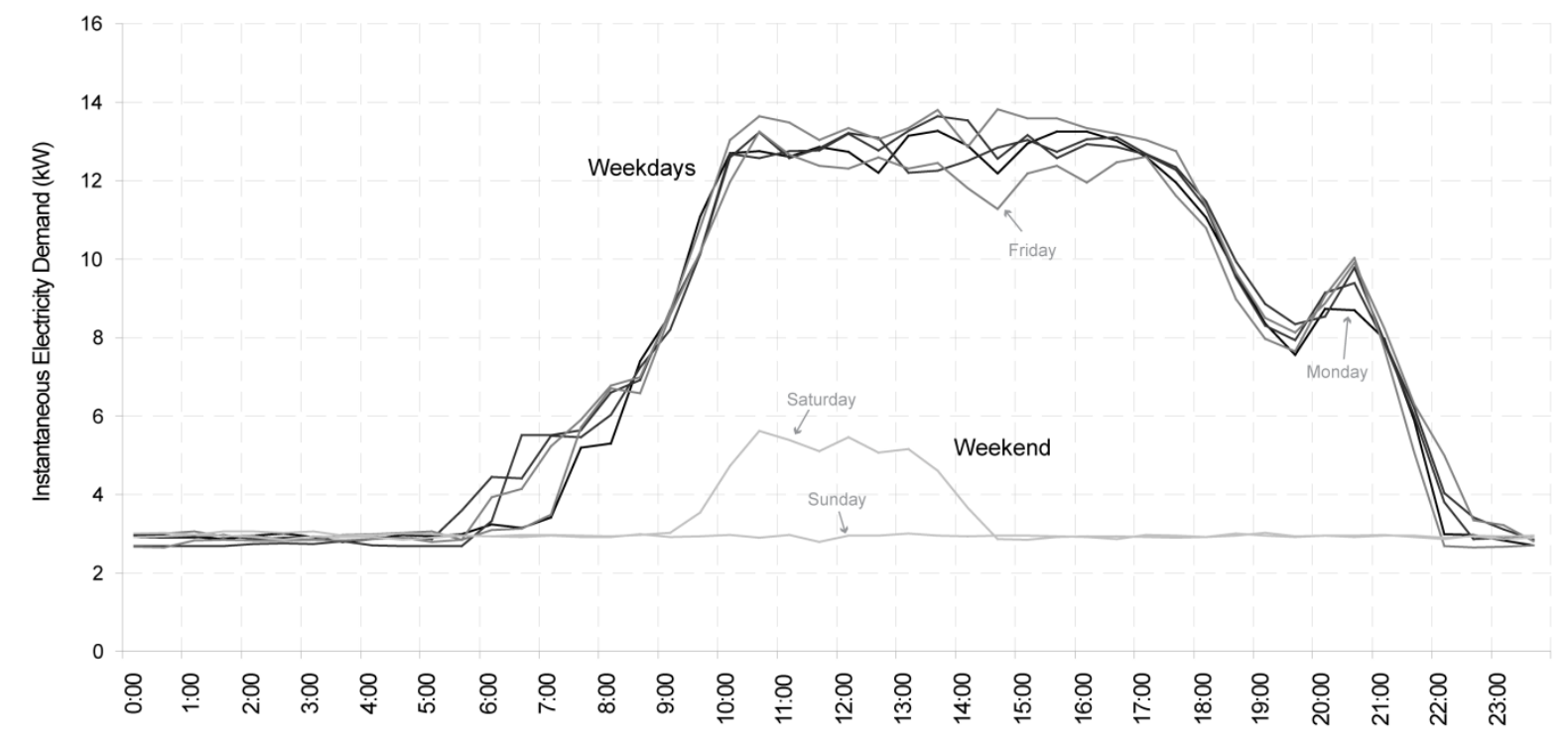

Figure 7: Monitored electricity consumption for 4th floor - Northeast zone.

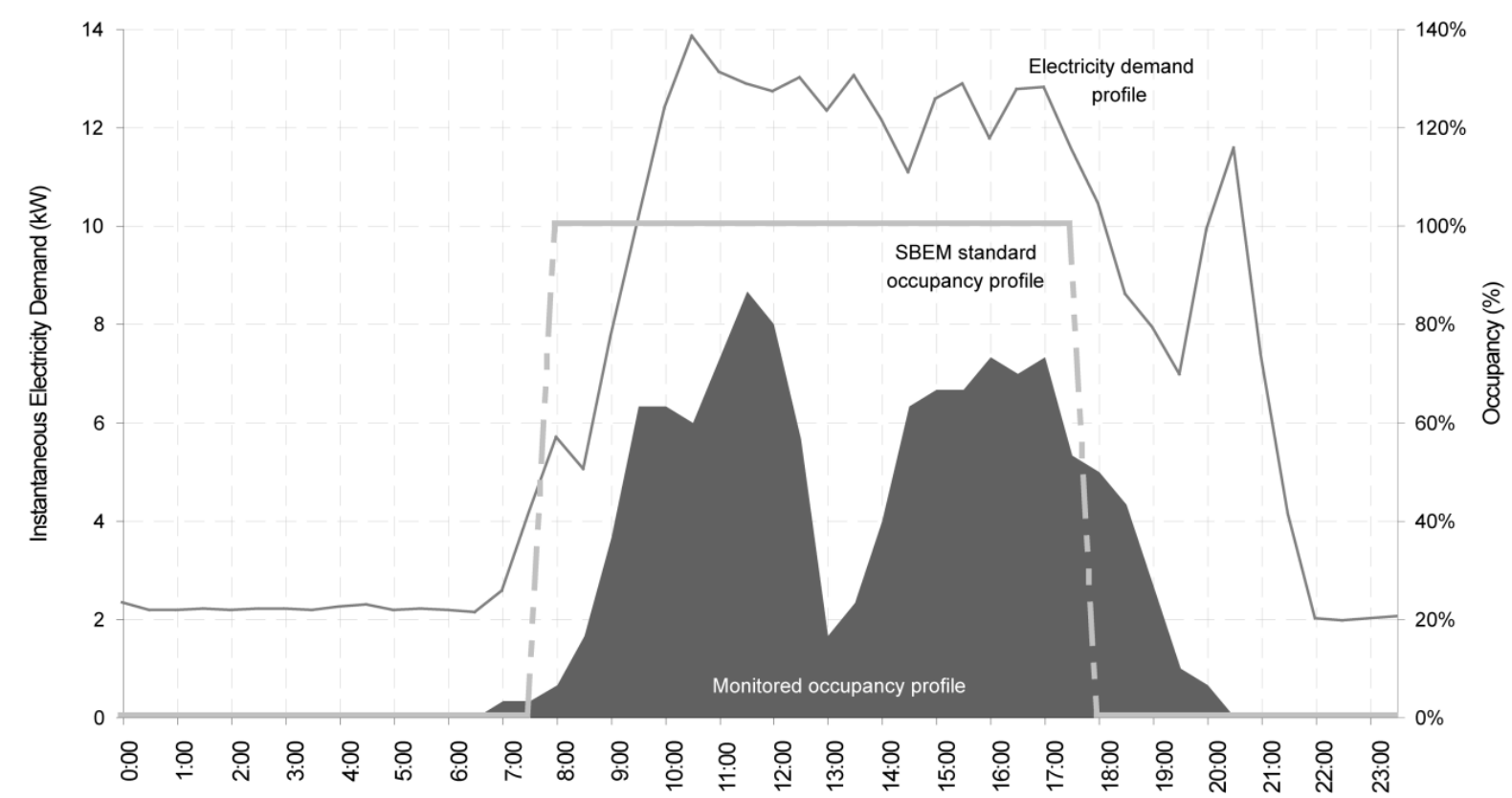

Figure 8: Relationship between monitored electricity consumption and occupancy profiles.

\subsection{Predictive models}

Following the detailed analysis of electricity consumption in the 4th floor NE zone, the acquired data was used to produce 5 predictive models of electricity consumption. These predictions refer to the annual electricity consumption for lighting, small power and catering for this specific zone, occupied by Tenant B. An increasing level of detail was used in each subsequent model, replacing typical assumptions with monitored data. The parameters used for each of the electricity demands are detailed in Table 2. It is worth 
mentioning that due to increasing complexities in the input parameters of small power and catering equipment, a spreadsheet approach was taken to predict annual electricity consumption. Although most DSMs will allow such detailed parameters to be used, the process of doing so can be quite onerous. In addition, most DSMs rely on a 'black box' approach, meaning that the user has no control over how the calculations are carried out [22], making it difficult to visualise the impact of such detailed inputs in the overall electricity consumption of the building. As such, a bottom-up approach to CIBSE TM22 was used to produce the predictive models. This methodology (illustrated earlier in Figure 2) has previously been used to predict electricity consumption [2, 23], allowing for detailed parameters such as load and usage factors to be used. This approach was used in predictive models 1 and 2 . Alternatively, metered data can be used to replace assumptions, increasing the accuracy of the model. This approach was used in models 3,4 and 5, where increasing amounts of data acquired from the monitoring study (mostly through the use of plug monitors) was used to replace standard assumptions regarding energy consumption of specific equipment. Information gathered through the monitoring of occupancy patterns was also used to substitute standard occupancy hours in model 5.

It is worth mentioning that the actual electricity consumption value displayed in Figure 9 was unknown at the time these predictive models were developed. The author was aware of the average consumption per $\mathrm{m}^{2}$ for Tenant $\mathrm{B}$ but did not have access to the actual consumption value for the specific zone being modelled.

Results from the predictive models are illustrated in Figure 9. The predictions are labelled 1-5 accordingly and reflect the inputs specified in Table 2. As seen, the predictions are compared against the actual electricity consumption, which is not subdivided into the specific end-uses due to the limitations of the sub-metering strategy of the building. Two benchmark values are also illustrated in the graph for further comparison. These were acquired from 'Energy Consumption Guide 19' (commonly referred to as ECON 19) and illustrate industry benchmarks for Typical (TYP) and Best Practice (BP) energy consumption for lighting, small power and catering in standard air conditioned office buildings with floor areas between $2000 \mathrm{~m}^{2}$ and $8000 \mathrm{~m}^{2}$ (i.e. Type 3) [25].

\begin{tabular}{|c|c|c|c|c|}
\hline Model & Brief description & Lighting & Small Power & Catering \\
\hline 1 & $\begin{array}{l}\text { Typical compliance model using lighting specification from the } \\
\text { design brief, using SBEM standard occupancy hours and } \\
\text { overlooking small power and catering equipment. }\end{array}$ & $\begin{array}{l}11 \mathrm{~W} / \mathrm{m}^{2} \\
2600 \mathrm{hrs} / \text { year }\end{array}$ & Not considered. & Not considered. \\
\hline 2 & $\begin{array}{l}\text { 'Enhanced' compliance model using industry rules of thumb to } \\
\text { account for small power loads [21], but overlooking catering } \\
\text { equipment. }\end{array}$ & $\begin{array}{l}11 \mathrm{~W} / \mathrm{m}^{2} \\
2600 \mathrm{hrs} / \text { year }\end{array}$ & $\begin{array}{l}15 \mathrm{~W} / \mathrm{m}^{2} \\
2080 \mathrm{hrs} / \text { year (due } \\
\text { to } 80 \% \text { usage factor) }\end{array}$ & Not considered. \\
\hline 3 & $\begin{array}{l}\text { Initial bespoke model using monitored data regarding the } \\
\text { installed lighting load as well as measured electricity demand } \\
\text { for basic small power and catering equipment. SBEM standard } \\
\text { occupancy hours were used accounting for an } 80 \% \text { usage } \\
\text { factor of small power equipment. }\end{array}$ & $\begin{array}{l}13 \mathrm{~W} / \mathrm{m}^{2} \\
2600 \mathrm{hrs} / \text { year }\end{array}$ & $\begin{array}{l}170 \text { laptops } \\
170 \text { screens } \\
5 \text { printers } \\
=11 \mathrm{~W} / \mathrm{m}^{2} \\
2080 \mathrm{hrs} / \text { year }\end{array}$ & $\begin{array}{l}1 \text { water heater } \\
1 \text { fridge } \\
=0.3 \mathrm{~W} / \mathrm{m}^{2} \\
2600 \mathrm{hrs} / \text { year }\end{array}$ \\
\hline 4 & $\begin{array}{l}\text { Intermediate bespoke model using monitored data for lighting } \\
\text { as well as measured electricity demand for all small power and } \\
\text { catering equipment installed. SBEM standard occupancy hours } \\
\text { were used once again with allowances for usage factor of small } \\
\text { power equipment. }\end{array}$ & $\begin{array}{l}13 \mathrm{~W} / \mathrm{m}^{2} \\
2600 \mathrm{hrs} / \text { year }\end{array}$ & $\begin{array}{l}170 \text { laptops } \\
170 \text { screens } \\
5 \text { printers } \\
8 \text { desk lamps } \\
6 \text { desk fans } \\
=11.5 \mathrm{~W} / \mathrm{m}^{2} \\
2080 \mathrm{hrs} / \text { year }\end{array}$ & $\begin{array}{l}1 \text { water heater } \\
1 \text { fridge } \\
1 \text { microwave } \\
1 \text { dishwasher } \\
2 \text { coffee machines } \\
=1 \mathrm{~W} / \mathrm{m}^{2} \\
2600 \mathrm{hrs} / \text { year }\end{array}$ \\
\hline 5 & $\begin{array}{l}\text { Advanced bespoke model using monitored data for lighting as } \\
\text { well as measured electricity demand for all small power and } \\
\text { catering equipment installed. Monitored hours of use were } \\
\text { used for all lighting, small power and catering equipment. }\end{array}$ & $\begin{array}{l}13 \mathrm{~W} / \mathrm{m}^{2} \\
3640 \mathrm{hrs} / \text { year }\end{array}$ & $\begin{array}{l}170 \text { laptops } \\
170 \text { screens } \\
5 \text { printers } \\
8 \text { desk lamps } \\
6 \text { desk fans } \\
=11.5 \mathrm{~W} / \mathrm{m}^{2} \\
\text { [monitored hours of } \\
\text { use per individual } \\
\text { equipment] }\end{array}$ & $\begin{array}{l}1 \text { water heater } \\
1 \text { fridge } \\
1 \text { microwave } \\
1 \text { dishwasher } \\
2 \text { coffee machines } \\
=1 \mathrm{~W} / \mathrm{m}^{2} \\
\text { [monitored hours of } \\
\text { use per individual } \\
\text { equipment] }\end{array}$ \\
\hline
\end{tabular}

Table 2: Input parameters used in each predictive model. 


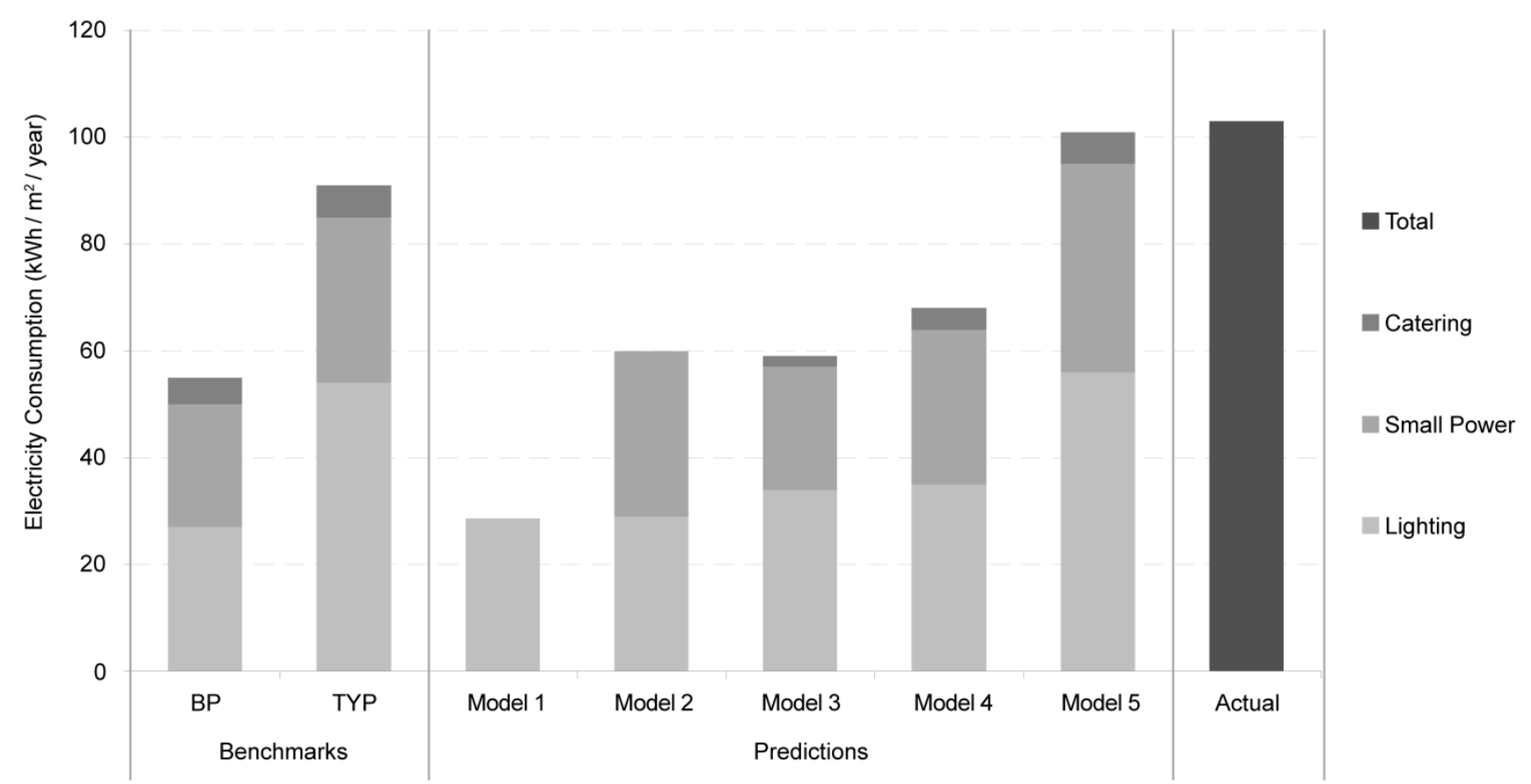

Figure 9: Comparison of benchmarks, predicted and actual electricity consumption.

As shown in Figure 9, the increased detail in the input parameters of models 1-5 have resulted in incremental increases of the predicted annual electricity consumption. By using a typical compliance model in prediction model 1 , the calculated electricity consumption was shown to be less than $1 / 3$ of the actual inuse consumption. The predicted value was then increased significantly in prediction model 2 when 'rules of thumb' published by the Building Services Research and Information Association (BSRIA) for small power consumption were used to account for the electricity demand of office equipment [24]. It is worth mentioning such rules of thumb are commonly used in DSMs when trying to predict energy consumption of buildings in-use [26]. In prediction model 3 , design specifications and rules of thumb were replaced by monitoring data of installed lighting and equipment. At this point however, only basic equipment were considered and SBEM standard occupancy hours were assumed. This resulted in a similar total prediction of electricity consumption, yet this total consisted of higher lighting loads and lower small power loads. This demonstrates that actual installed lighting loads were higher than specified at design stage. Meanwhile the small power prediction seems to have been fairly conservative by having considered only basic office and catering equipment. In prediction model 4, all installed equipment were included, resulting in an increase of approximately 15\% in the total electricity consumption. Finally, in prediction model 5, the SBEM standard occupancy hours were replaced by monitored occupancy hours. By doing so, the predicted electricity consumption came within $3 \%$ of the actual consumption of the building in-use. This small discrepancy could be associated with the fact that the predictions were based on measurements from a single day. As such, the model assumes a typical operation throughout the entire year, disregarding variations in both occupancy and energy use profiles that are bound to occur.

When comparing the results from the predictive modelling against the ECON 19 benchmarks, it is possible to conclude that the final prediction is only slightly higher than the typical benchmark for a Type 3 office building. However, when considering that Tenant B had the second lowest consumption per $\mathrm{m}^{2}$ in the building, one would expect it to be lower than the typical benchmark and perhaps closer to best practice. Considering that the ECON 19 benchmarks were compiled over 10 years ago, they might not be representative of current office buildings. With the fast advancements in the design of low energy ICT equipment, energy consumption due to small power would be expected to have decreased in the last decade. However, current offices are now run for longer hours and tend to contain more 
items of small power equipment. The same would be expected for lighting and catering, resulting in similar proportions of electricity being consumed by each end use. The lack of more up-to-date benchmarks makes it hard for further conclusions to be drawn.

\subsection{Methodology validation}

In order to validate the methodology used to generate the predictive models, the same approach was used to model another zone in the building occupied by a different tenant (i.e. 2nd floor South-West zone occupied by Tenant D). Once again a walk through inspection was undertaken to determine the quantities of installed equipment throughout the zone. Plug monitors were then used to log the energy consumption of different small power and catering equipment, and variations in occupancy density were also monitored via half-hour inspections throughout the day. Acquired data was incrementally used to inform the input parameters for the predictive models, as detailed in Table 3.

\begin{tabular}{|c|c|c|c|}
\hline Model & Lighting & Small Power & Catering \\
\hline 1 & $\begin{array}{l}11 \mathrm{~W} / \mathrm{m}^{2} \\
2600 \mathrm{hrs} / \text { year }\end{array}$ & Not considered & Not considered \\
\hline 2 & $\begin{array}{l}11 \mathrm{~W} / \mathrm{m}^{2} \\
2600 \mathrm{hrs} / \text { year }\end{array}$ & $\begin{array}{l}15 \mathrm{~W} / \mathrm{m}^{2} \\
2080 \mathrm{hrs} / \text { year } \\
\text { (due to } 80 \% \\
\text { usage factor) }\end{array}$ & Not considered \\
\hline 3 & $\begin{array}{l}\text { Fixed lighting } \\
=12.8 \mathrm{~W} / \mathrm{m}^{2} \\
2600 \mathrm{hrs} / \text { year }\end{array}$ & $\begin{array}{l}40 \text { laptops } \\
70 \text { desktops } \\
110 \text { screens } \\
4 \text { printers } \\
=11.6 \mathrm{~W} / \mathrm{m}^{2} \\
2080 \mathrm{hrs} / \text { year }\end{array}$ & $\begin{array}{l}1 \text { water heater } \\
1 \text { fridge } \\
=0.3 \mathrm{~W} / \mathrm{m}^{2} \\
2600 \mathrm{hrs} / \text { year }\end{array}$ \\
\hline 4 & $\begin{array}{l}\text { Fixed lighting } \\
\text { plus decorative } \\
\text { and task } \\
\text { lighting } \\
=17.3 \mathrm{~W} / \mathrm{m}^{2} \\
2600 \mathrm{hrs} / \mathrm{year}\end{array}$ & $\begin{array}{l}40 \text { laptops } \\
70 \text { desktops } \\
110 \text { screens } \\
4 \text { printers } \\
2 \text { desktop printers } \\
3 \text { plasma TVs } \\
=12.6 \mathrm{~W} / \mathrm{m}^{2} \\
2080 \mathrm{hrs} / \text { year }\end{array}$ & $\begin{array}{l}1 \text { water heater } \\
1 \text { fridge } \\
3 \text { glass front fridges } \\
2 \text { microwave } \\
1 \text { dishwasher } \\
2 \text { coffee machines } \\
2 \text { vending machines } \\
=2.3 \mathrm{~W} / \mathrm{m}^{2} \\
2600 \mathrm{hrs} / \text { year }\end{array}$ \\
\hline 5 & $\begin{array}{l}\text { Fixed lighting } \\
\text { plus decorative } \\
\text { and task } \\
\text { lighting } \\
=17.3 \mathrm{~W} / \mathrm{m}^{2} \\
3120 \mathrm{hrs} / \mathrm{year}\end{array}$ & $\begin{array}{l}40 \text { laptops } \\
70 \text { desktops } \\
110 \text { screens } \\
4 \text { printers } \\
2 \text { desktop printers } \\
3 \text { plasma TVs } \\
=12.6 \mathrm{~W} / \mathrm{m}^{2} \\
\text { [monitored hours } \\
\text { of use per } \\
\text { individual } \\
\text { equipment] }\end{array}$ & $\begin{array}{l}1 \text { water heater } \\
1 \text { fridge } \\
3 \text { glass front fridges } \\
2 \text { microwave } \\
1 \text { dishwasher } \\
2 \text { coffee machines } \\
2 \text { vending machines } \\
=2.3 \mathrm{~W} / \mathrm{m}^{2} \\
\text { [monitored hours of } \\
\text { use per individual } \\
\text { equipment] }\end{array}$ \\
\hline
\end{tabular}

Table 3: Input parameters used in predictive models for methodology validation
The previous investigation into the energy use of Tenant $D$ had revealed that a significant proportion of employees routinely left their computer on overnight in order to run time consuming tasks. In order to account for this behaviour into the predictive models, an assumption was made that $20 \%$ of computers were constantly left on. This assumption was made based on rough estimated provided by Tenant D's IT technicians. Figure 10 compares the results of the predictive models with the actual electricity use for the zone being analysed. It also illustrated the results from the previous predictive models for the zone occupied by Tenant $B$.

As seen in Figure 10, the first two models are identical for both zones. This is due to the fact that they are compliance models, which do not account for actual installed loads or any specific characteristics of the individual zones. Models $3-5$ provide increasing levels of detail into the installed equipment within each of the zones, progressively increasing the accuracy of the models. Once again it is the final step of adjusting the occupancy hours that seems to have the highest impact towards achieving an increasingly accurate prediction.

During this validation exercise, the final model achieved a prediction within $6 \%$ of the actual electricity consumption of the zone, being slightly less accurate than the initial set of predictive models. This could be related to the assumptions made regarding the proportion of employees who leave their computer on overnight, suggesting that more than $20 \%$ of computers are constantly left on overnight. This emphasises the importance of minimising the use of assumptions in order to achieve realistic predictions.

\subsection{Conclusion}

This paper has discussed the existence of a gap between predicted and actual energy consumption in non-domestic buildings. It has highlighted the main causes of such discrepancies, identifying POE as a key tool for understanding this issue further. It also identified the potential for using POE results to inform predictions, enabling better assumptions to be used in detailed energy modelling. A case study revealed that by 
conducting basic monitoring exercises it is possible to feed results into energy models and gain a more accurate prediction of a building's actual performance (within $3 \%$ of actual consumption for this specific study). A validation exercise demonstrated that replicating the methodology within a different zone in the building produced results within $6 \%$ of the actual energy use for the zone. Despite the limited applicability of this methodology to non-speculative buildings, the results are encouraging and demonstrate that reliable predictions can be obtained for lighting and small power loads by using realistic assumption in the modelling process. It is also worth mentioning that improved predictions for electricity consumption due to lighting and equipment can also inform better assumptions regarding internal loads, which can in turn improve the prediction of cooling and heating demand in a building.

Key findings from this study highlight the need for better understanding of occupancy patterns and behaviour in office buildings. Variations in the electricity consumption of different tenants occupying the same building have demonstrated that modelling software should account for different occupancy patterns and behaviours if realistic predictions are to be achieved. In addition, a clear correlation was observed between monitored occupancy profiles and tenant electricity consumption. It should be noted however, that energy demand can vary largely with tenant behaviour throughout the day (not only when they arrive or leave). The impact of management was not analysed in this study due to its focus on tenant consumption. It is important to highlight, however, that management decisions, such as the running of ICT updates outside of occupancy hours, were observed to have a significant impact on the tenant consumption. Inconsistencies between design specification and installed lighting loads were also observed to have a considerable impact on the discrepancy between predicted and actual electricity use.

If the UK is to experience real reductions in its $\mathrm{CO}_{2}$ emissions, it is imperative that we start achieving energy efficiency in practice. With Building Regulations relying heavily on predictive indicators of performance, it is vital that we understand the limitations of the current compliance modelling and aim to predict realistic energy consumption levels by using detailed DSMs that account for realistic occupancy and management behaviours. The widespread practice of POE can help us understand how occupants and facilities managers interact with the built environment. It can also provide valuable information regarding the performance of the current building stock.
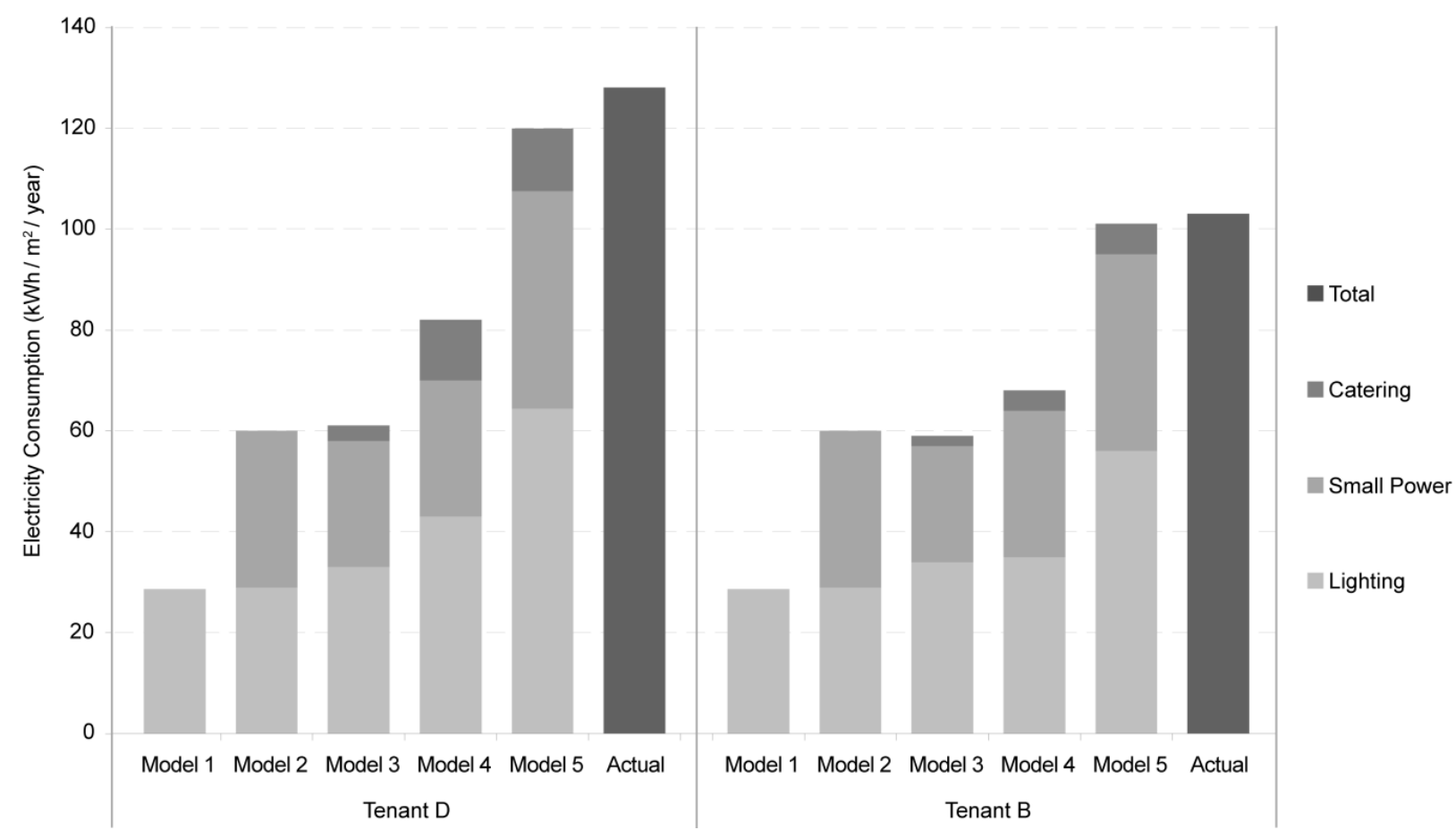

Figure 10: Predictive model results and actual electricity consumption in both zones investigated. 


\subsection{Future work}

Future work will seek to use detailed POE data to develop a set of evidence based benchmarks for energy consumption in office buildings. It is envisioned that these benchmarks will inform designers regarding the impact of occupancy and management on the actual energy consumption of offices. Moreover, it should enable the use of more realistic input parameters in energy models, bringing the predicted figures closer to reality.

\subsection{Acknowledgements}

The corresponding author would like to thank the EPSRC, Loughborough University and AECOM for funding this research.

\subsection{References}

[1] Demanuele, C., Tweddell, T. \& Davies, M., 2010. "Bridging the Gap Between Predicted and Actual Energy Performance in Schools". World Renewable Energy Congress XI. 25-30 September 2010, Abu Dhabi, UAE

[2] Bordass, B., Cohen, R. \& Field, J., 2004. Energy Performance of Non-Domestic Buildings - Closing the Credibility Gap, International Conference on Improving Energy Efficiency in Commercial Buildings. Frankfurt, Germany.

[3] Probe archive held by the Usable Buildings Trust (UBT) website:

http://www.usablebuildings.co.uk/Pages/UBPro bePublications1.html [accessed 17/11/2011].

[4] Bordass, B., Cohen, R., Standeven, M. \& Leaman, A., 2001. "Assessing Building Performance in Use 3: Energy Performance of Probe Buildings". Building Research and Information, vol. 29, no. 2, pp. 114-128.

[5] Climate Change Act, 2008. Carbon Targeting and Budgeting, Chapter 27, Part 1 The Target for 2050, Her Majesty's Stationery Office Limited, UK.

[6] Raslan, R., Davies, M. \& Doylend, N., 2009. "An Analysis of Results Variability in Energy Performance Compliance Verification Tools".
Eleventh International IBPSA Conference, 2730 July, Glasgow, Scotland.

[7] Carbon Trust website:

http://www.carbontrust.co.uk/emerging-

technologies/current-focus-

areas/buildings/case-

studies/pages/default.aspx [accessed

17/11/2011].

[8] Carbon Trust, 2011. Closing the Gap Lessons learned on realising the potential of low carbon building design. CTG047, July 2011. London: Carbon Trust.

[9] CarbonBuzz website: http://www.carbonbuzz.org [accessed 17/11/2011].

[10] Hamilton, I., Steadman, P. \& Bruhns, H., 2011. CarbonBuzz - Energy Data Audit. UCL Energy Institute, July 2011.

[11] Lowe, R. \& Oreszczyn, T., 2008.

"Regulatory Standards and Barriers to Improved Performance for Housing". Energy Policy, vol. 36, pp. 4475 - 4481

[12] Oreszczyn, T. \& Lowe, R., 2010. "Challenges for energy and buildings research: objectives, methods and funding mechanisms". Building Research and Information, vol 38, issue 1, pp 107-122.

[13] De Wit, M. S., 1995. "Uncertainty Analysis in Building Thermal Modelling". Proceedings of International Building Performance Simulation Association, 14-16 August, Madison, USA.

[14] Chartered Institute of Building Services Engineers, 2006. CIBSE TM33: Standard tests for the assessment of building services design software. London, UK.

[15] Way, M. \& Bordass, B., 2005. "Making feedback and post-occupancy evaluation routine 2: Soft Landings - involving design and building teams in improving performance". Building Research and Information, vol. 33, no. 4, 353-360. 
[16] Preiser, W., Rabinowitz, H. \& White, E., 1987. Post-occupancy evaluation. British Library; Cardiff Edinburgh ; UCL (University College London) edn, Van Nostrand Reinhold.

[17] Cooper, I., 2001. "Post-occupancy evaluation - where are you?" Building Research \& Information, vol. 29, no. 2, 158-163.

[18] Turpin-Brooks, S. \& Viccars, G., 2006. "The development of robust methods of post occupancy evaluation". Facilities, vol. 24, no. 5/6, 177-196.

[19] CIBSE, 1999. CIBSE TM22: Energy Assessment and Reporting Methodology Office Assessment Method. London, UK.

[20] CIBSE, 2006. CIBSE TM22: Energy Assessment and Reporting. London, UK.

[21] Technology Strategy Board website: https://ktn.innovateuk.org/web/buildingperformance-evaluation
[22] White, A. \& Holmes, M., 2009. "Advanced Simulation Applications using ROOM".

Eleventh International IBPSA Conference, 2730 July, Glasgow, Scotland.

[23] Cohen, R. \& Bordass, B., 2006. "Report on Proposed Energy Benchmarking Systems for Six Sectors". Technical Report presented by Energy for Sustainable Development Limited for EPLabel. Wiltshire, UK

[24] BSRIA, 2003. Rules of Thumb: Guideline for Building Services. $4^{\text {th }}$ edition, London, UK.

[25] BRECSU, 2000. Energy Consumption Guide 19: Energy use in offices. Building Research Energy Conservation Support Unit, Watford, UK.

[26] Dunn, G. \& Knight, I., 2005. "Small Power Equipment Loads in UK Office Environments". Energy and Buildings, vol.37, 87-91. 